\title{
An Analysis of Cognitive Reading Strategies Used in Reading Comprehension
}

\author{
Nur Intan Asmara \\ Universitas Pendidikan Indonesia, Bandung, Indonesia \\ nurintanasmara@gmail.com
}

\begin{abstract}
Various kinds of English texts are presented in Senior High School, but most of the students often have problems in understanding the texts because they cannot comprehend the texts well. This might be because they have never been exposed to the reading strategies and never known that there are strategies for reading. This study is to investigate which cognitive reading strategies frequently used by the first grade of Senior High School students in Rancaekek in enhancing their reading comprehension. In obtaining the data, 'A self-report questionnaire' was administered to the 30 students and they are asked to give their responses toward the strategy that they used in reading. The data were then analyzed by using instruments adapted from Format Cognitive Reading Strategies. The result shows that there were only 8 strategies that are frequently used by almost half of the participants in this study. It can be concluded that the students should be informed with cognitive reading strategies in helping them to comprehend the text. And last, it is suggested that, for further study to investigate not only cognitive reading strategy but also metacognitive strategy.
\end{abstract}

Keywords: Cognitive reading strategy, Reading Comprehension.

\section{INTRODUCTION}

In senior high school, a number of reading texts are presented in learning English, and the students are expected to answer all the questions from the text given. But most of the students find some difficulties in comprehending the text and they do not have any ideas in answering the questions. This might be because they have never been exposed to the reading strategies and never known that there are strategies for reading. Actually, students can understand the text more effectively if they are able to use appropriate reading strategies. The use of effective reading strategies is important as they help students to minimize time and effort to comprehend a particular text.

Generally, most of the students do not concern with their reading behaviours and they do not know how to guess the meaning of unfamiliar words within the context. They tend to translate word by word while interpreting the text, and although they may know the meaning of each word, they are still incapable to comprehend the ideas conveyed in the text. That's why this study is conducted to investigate which cognitive reading strategies frequently used by the First year students in one of Senior High Schools in Rancaekek, Bandung in enhancing their reading comprehension. Meanwhile, the scope of the study is delimited into cognitive reading strategies used by the first year of senior high school students.
Reading serves the wider role of extending our general knowledge of the world and it is very important, so some strategies are required (Wallace, 1992). Learning strategies have learning facilitation as a goal and are intentional on the part of the learner (Weinstein \& Mayer, 1986). The goal of a strategy use is to "affect the learner's motivational or affective state, or the way in which the learner selects, acquires, organizes, or integrates new knowledge".

Oxford (1990) stated that there are two kinds of learning strategies; direct strategies and indirect strategies. Direct strategies consist of memory strategies, cognitive strategies, and compensation strategies. Meanwhile, indirect strategies consist of metacognitive strategies, affective strategies, and social strategies. Cognitive strategies are the most popular strategies used in reading as stated by Ozek and Civelek (2006)

Cognitive strategies are seen as mental processes directly concerned with the processing of information in order to learn for obtaining, storage, retrieval or use of information (Williams \& Burden, 1997). They are more limited to specific learning tasks and involve more direct manipulation of the learning material itself (Brown, 1994). Cognitive strategies enable the learner to manipulate the language material in direct ways, e.g., through reasoning, analysis, note-taking, summarizing, synthesizing, outlining, reorganizing information to develop stronger schemas (knowledge structure), practicing in naturalistic setting, and practicing structures and sound formally (Oxford L. R., 2003).

Cognitive strategies for listening and reading comprehension which include rehearsal or repeating, organization or grouping and classifying words, inferencing, summarizing, deduction, imagery, transfer or using known linguistics information to facilitate new learning task, elaboration (O'Malley \& Chamot, 1990). They stated that the use of cognitive strategies in reading can help someone to be a proficient reader. This is supported by the theories of cognitive reading strategies and the result of the study conducted by Ozek and Civelek (2006).

A number of researchers have conducted some study toward the cognitive reading strategy. Ozek and Civelek (2006) try to find out which reading strategies are generally employed by ELT students while reading a text, and which reading strategies are needed to be developed to understand the text better, and therefore, to continue academic studies successfully. Research on the effects of cognitive strategies on reading performance suggests that relating the title, 
illustrations/pictures and background knowledge to the text, skimming, using dictionary parsimoniously, guessing, remembering a word through situations, rereading, using the first language as a base, visualizing events, being careful about how the text is organized, making notes and summaries of the important information, and classifying words are the strategies help readers to improve their reading ability significantly and therefore, these strategies should be neglected in the foreign or second language reading curriculum.

The study assesses the trends of the cognitive reading strategies training and its impact on the comprehension skill of EFL learners in the secondary schools (Bachore, 2014). This study shows that the reading strategy training has a positive impact on developing the students' reading skills. This finding agrees with the study carried out by (Song, 1998) which says that reading strategy instruction enhances the learners' reading ability. But, the instruction should be attended carefully following the procedures which are proposed by the scholars. To sum up, the experiment clearly shows that cognitive reading strategy training facilitates the learners' comprehension skill.

Based on the explanation above, it is assumed that it is important to know the cognitive reading strategies frequently used by the first year students in reading comprehension. It is hoped that students will make use of many useful reading strategies in order to improve their reading comprehension of English materials and their content subjects as well.

The problems to be investigated in this study can be formulated as: which cognitive reading strategies are frequently used by the first year of senior high school students in enhancing their reading comprehension?

This study employs cognitive reading strategies identified by Oxford (1990) and those proposed by O'Maley and Chamot (1990) which were also used as the theoretical foundation in the previous study conducted by Ozek and Civelek (2006).

The types of cognitive reading strategies investigated in this study are: resourcing, repetition, grouping, deduction, imagery, getting the idea quickly, elaboration, inferencing, note-taking, and summarizing. These strategies are used in the questionnaire as the instrument to gain the data from the respondents. Resourcing: is using the target language reference materials such as dictionaries, encyclopedias, or textbooks (O'Malley \& Chamot, 1990). In this study, this is the strategy of using dictionary for important words. Repetition or rehearsal: is repeating the names of items or objects to be remembered (O'Malley \& Chamot, 1990). Oxford (1990) also states that in reading, the strategy of repeating can be reading a passage more than once to understand it more completely. Grouping: according to O'Malley and Chamor (1990), grouping is classifying words, terminology, or concepts according to their semantic or syntactic attributes. In this study, grouping is the strategy of classifying the words according to their grammatical categories. Deduction: according to O'Malley and Chamor (1990), deduction strategy is applying rules to the understanding of language. Oxford (1990) states that this is a top-down strategy leading from general to specific. In this study, this strategy is represented by the strategy of reading the first line of every paragraph to understand the whole text. Imagery is using visual images (either generated or actual) to understand or remember new verbal information (O'Malley \& Chamot, 1990). Meanwhile, Oxford (1990) states this strategy as a good strategy to remember what has been read in the new language to create a mental image of it. Getting the Idea Quickly: Oxford (1990) stated that the strategy of getting the idea quickly constitutes with skimming strategy and scanning strategy. Skimming involves searching for the main ideas the speaker wants to get across, while scanning means searching for specific details of interest to the learner. Skimming is a quick, superficial reading of a text in order to get the gist of it while scanning is looking for specific information in the text and ignoring the rest (Richards, 1997). According to O'Malley and Chamot (1990) elaboration is linking ideas contained in new information, or integrating new ideas with known information. Inferencing is using information in text to guess the meaning of new linguistics items, predict outcomes, or complete missing parts (O'Malley \&Chamot, 1990). In this study, inferencing is the strategy of using the title to predict the content of the text. Note-taking strategy: as writing down key words and concepts in abbreviated verbal, graphic, or numerical form while listening or reading (O'Malley \& Chamot, 1990). Note-taking makes students active participants in their learning, helps them organize important concepts, remember information, and becomes one of their study aids. Summarizing: according to O'Malley and Chamot (1990), summarizing is intermittently synthesizing what one has heard to ensure the information has been retained.

\section{RESEARCH METHODOLOGY}

The method used in this study is to find the answer of the research question. 'Which cognitive reading strategies are frequently used by the first year of senior high school students in enhancing their reading comprehension?' Descriptive qualitative procedure was used in this study to identify students' cognitive reading strategies as proposed by Ozek and Civelek (2006) as the main theory.

There were 30 students participated in this study as the respondents. They are at the first grade of senior high school. They were chosen randomly as the participant in this study as they were considered having some problems in comprehending the texts, since they had a transition period from the junior high school to senior high school.

The questionnaire was administered to the respondent and they were asked to give their responses toward their strategy used in reading comprehension. The questionnaire consisted of 30 closed-ended items. The respondents choose one option that best aligns with their view. The data gathered from the respondents were then described in the form of simple description; therefore, the Likert Scale was used with the criteria exemplified in Table 1.Questionnaires were administered to the respondents to gain the information about their reading strategies in enhancing their reading comprehension in their daily reading activity. Meanwhile, the 
questionnaire was adapted from Ozek and Civelek (2006). The questionnaire consisted of 30 closed-ended items. It represents good reading strategies and poor reading strategies based on the theories in O'Malley and Chamot (1990) and Ozek and Civelek (2006). There were 22 items belong to cognitive strategies in which 17 items belong to cognitive reading strategies. These 17 items can be grouped in under 10 categories: resourcing, repetition, grouping, deduction, imagery, getting the idea quickly, elaboration, inferencing, note-taking, and summarizing. The complete lists of the items are presented in appendix.

The Likert scale used in this study is to measure respondents' attitudes by asking the extent to which they agree or disagree with a particular question or statement. A typical scale might be "Strongly disagree, Disagree, Neutral, Agree, Strongly agree". It is drawn in the Table 1

Table 1. Students' Reading Strategies Score for Questionnaire

\begin{tabular}{ll}
\hline CATEGORY & SCORE \\
\hline Never & 1 \\
\hline Rarely & 2 \\
\hline Sometimes & 3 \\
\hline Usually & 4 \\
\hline Always & 5 \\
\hline
\end{tabular}

By using this Likert scale, the students' responses towards the 30 strategies were scored and summed. The students' total score were regarded as their score in reading strategies. Furthermore, the scores from students were calculated to find the intensity of use of every indicator in the questionnaire. Regarding to the most frequently used strategy responses, the scores of Usually and Always were combined to be the scores of $\mathrm{U}+\mathrm{A}$. The combinations were made to examine the frequency of using strategies in which the responses U+A indicated that the students used the strategy frequently. Such combination is beneficial to measure the students' positive responses towards the learning strategies. The score, at the end were presented in the form of percentage.

\section{RESEARCH FINDINGS AND DISCUSSION}

The frequency of the use of the strategy is calculated based on the number of the students choosing the strategy. From the whole strategy in the questionnaire, there is a tendency that all students use all the strategies as evidence that they filled the questionnaire scales. The strategies mostly used by the students are 'Having the picture of the events in the text in mind' and 'Reading every word' with $66.67 \%$ occurrences, whereas the least frequently strategies used are 'Re-reading a sentence', 'Keep the purpose of reading text in mind', and 'Making paraphrase while reading' with $13.33 \%$ occurrences.

The table below is the quality of reading strategies frequently used by more than half of the respondents based on the questionnaire.
Table 2. Results of questionnaire

\begin{tabular}{|c|c|c|c|}
\hline \multirow[t]{2}{*}{ No. } & \multirow[t]{2}{*}{ STRATEGY } & $\mathbf{U}+\mathbf{A}$ & $\begin{array}{l}\text { TOTAL } \\
\mathbf{U}+\mathbf{A}\end{array}$ \\
\hline & & (F) & $(\%)$ \\
\hline 1 & $\begin{array}{l}\text { Having the picture of the events in } \\
\text { the text in mind }\end{array}$ & 20 & 66.67 \\
\hline 2 & Reading every words & 20 & 66.67 \\
\hline 3 & $\begin{array}{l}\text { Reading without looking at the title } \\
\text { to find out what the text might be } \\
\text { about }\end{array}$ & 19 & 63.33 \\
\hline 4 & $\begin{array}{l}\text { Guessing the meaning of a word } \\
\text { from the context }\end{array}$ & 17 & 56.67 \\
\hline 5 & $\begin{array}{l}\text { Reading without writing anything, } \\
\text { just keep it in mind }\end{array}$ & 17 & 56.67 \\
\hline 6 & $\begin{array}{l}\text { Looking up every unknown word in } \\
\text { the dictionary }\end{array}$ & 16 & 53.33 \\
\hline 7 & $\begin{array}{l}\text { Reading the title and imagining what } \\
\text { the text might be about }\end{array}$ & 15 & 50 \\
\hline 8 & $\begin{array}{l}\text { Using dictionary for the important } \\
\text { words }\end{array}$ & 15 & 50 \\
\hline
\end{tabular}

Based on the description in the table above, it can be concluded that the strategy of having the picture of the events in the text in mind achieves the highest percentage of all. The response from the participants is about $66.67 \%$. It is good to know that most students have employed good reader strategy (i.e visualizing and envisioning) in their reading activity.

The second strategy that mostly used by the respondents is reading every words. It is found that $66.67 \%$ respondent used this strategy. The result was in contrast to good reading strategy i.e skipping some of the unknown words. It is not good because most of the first year students were not yet become an efficient reader and need to be taught the strategy of reading.

The strategy 'reading without looking at the title to find out what the text might be about' gained $63.33 \%$ from the total of respondents. This means that more than half participants can't read more quickly and effectively. Teachers need to guide them more about this because previewing title can help students to read more quickly and effectively.

The strategy of guessing the meaning of a word from the context reaches $56.67 \%$ from the total of respondents. This is good for the students that to some extent, the students have good vocabulary skill in reading. As stated at the beginning that guessing the meaning of a word from the context is the most useful vocabulary skill that readers can have.

Reading without writing anything gained $56.67 \%$. It means that teachers need to inform the students that note-taking strategy is good reading strategy. It is a good idea to take note from textbook. Note taking makes students active participants in their learning, helps them organize important concepts, remember information, and becomes one of their study aids. It seems that, most of the students do not use this strategy.

$53.33 \%$ participants use looking up every unknown word in the dictionary in their reading activity. Actually, in cognitive reading strategies, using dictionary is suggested to find out the meaning of important words in the text, but, the 
students also can guess the meaning based on the context. Using dictionary for every unknown word is not effective in reading strategy. Teacher needs to give some suggestions to their students in this reading activity.

$50 \%$ participants in this study read the title and imagining what the text might be about. They can imagine the content of the text based on the title. It means that half of the participant can read quickly and effectively. This is good for the students as one of effort in comprehending the text.

Finally, 50\% participants prefer to consult dictionary for the important words. This is good because it means that they already use good strategy in reading.

The result from the questionnaire shows that only four strategies belong to cognitive reading strategies that have been frequently used by more than half of the students. Actually in the previous chapter, we can see that there are 10 categories (17 items) belong to cognitive reading strategy used in this study. But more than half of the respondents only use four categories in their reading activity. It can be interpreted that, teachers need to develop more and inform this strategy to the students to help them to be good reader in helping them to comprehend the text effectively. The students need to be taught this strategy and practice it in their reading activity. This strategy can help students understand and comprehend the text well that will lead them to be a good language learner.

\section{CONCLUSION AND RECOMMENDATION}

From the data, it can be concluded that only four strategies belong to cognitive reading strategies that have been frequently used by more than half of the students. The strategies that they employed in reading are having the picture in the text in mind, reading the title and imagining what the text might be about, guessing the meaning of a word from context, using a dictionary for the important word.

It is suggested that cognitive reading strategies should be taught to the students especially for the poor reader students who do not use cognitive reading strategies in reading. Teacher needs to explain the types of cognitive reading strategies and explain the benefits of using each strategy in reading. They also need to be informed some good reading strategies in reading, not only cognitive reading strategies. The students should be informed the appropriate strategy to use when they try to comprehend the text, for example, when they found a difficult word in the text, they will try to guess the meaning based on the context. Other example, when the students try to find out the main idea of the text, they will find it at the beginning of the text or at the last part of the text, etc.

As suggestion, it is suggested that for further study to have more items in the questionnaire (good reading strategies and poor reading strategies) to prevent bias. It will give more clear information to the teacher in gaining the students' responses. It is also suggested that, in obtaining the information from students to have an interview session with them. The relation between the learner styles and the strategy used can be another investigating area since it is believed that differences in the learning styles of the students may affect their strategy used.

\section{REFERENCES}

Bachore, M. (2014). Cognitive Reading Strategy Training and Its Effects on EFL Learners' Comprehension Skills: The Case of High School Learners. International Journal of Research (IJR), 1(4)

Brown, H. (1994). Principle of language Learning and Teaching . New Jersey: Prentice Hall Regents.

O'Malley, J., \&Chamot. (1990). A Learning Strategies in Second Language Acquisition. New York: Cambridge University Press.

Oxford, L. R. (2003). Language Learning Style and Strategies. Learning style \& Strategies/ Oxford, GALA, 12.

Oxford, R. L. (1990). Language Learning Strategies: What Every Teacher Should Know. New York: Newbury House Publishers.

Ozek, Y., \& Civelek, M. (2006). A Study on the Use of Cognitive Reading Strategies by ELT Students. Asian EFL Journal. Professional Teacher Articles,

Richards, C. J. (1997). From Reader to Reading Teacher: Issue and Strategies for SL Classroom. New York: Cambridge Language Education.

Song, M. (1998). Teaching eading strategies in an ongoing EFL niversity reading classsroom. Asian Journal of English Language Teaching, 8, 41-54.

Wallace, C. (1992). Language Teaching: A scheme for Teacher Education. Reading. Oxford: Oxford University Press.

Weinstein, C., \& Mayer, R. (1986). The teaching of learning strategies. In O'Malley\&Chamot. Learning Strategies in Second Language Acquisition. Cambridge: Cambridge University Press.

Williams, M., \& Burden, R. (1997). Psychology for Language Teachers: A Social Constructivist Approach. Cambridge: Cambridge University Press. 